\title{
A Field Investigation of Solubility and Food Chain Accumulation of Biosolid-Cadmium Across Diverse Soil Types
}

\author{
Mike J. McLaughlin, ${ }^{\mathrm{A}, \mathrm{B}, \mathrm{H}}$ Mark Whatmuff, ${ }^{\mathrm{A}, \mathrm{C}}$ Michael Warne, ${ }^{\mathrm{A}}$ Diane Heemsbergen, ${ }^{\mathrm{A}}$ \\ Glenn Barry, ${ }^{\mathrm{D}}$ Mike Bell, ${ }^{\mathrm{E}}$ David Nash, ${ }^{\mathrm{F}}$ and Deb Pritchard ${ }^{\mathrm{G}}$ \\ A Centre for Environmental Contaminants Research, CSIRO Land and Water, Glen Osmond, SA 5064, Australia. \\ ${ }^{B}$ School of Earth and Environmental Sciences, The University of Adelaide, SA 5005, Australia. \\ ${ }^{C}$ NSW Department of Primary Industries, Locked Bag 4, Richmond, NSW 2753, Australia. \\ D Department of Natural Resources and Water, Indooroopilly, Qld 4068, Australia. \\ E Department of Primary Industries and Fisheries, Kingaroy, Qld 4610, Australia. \\ ${ }^{F}$ Department of Primary Industries, Ellinbank, Vic. 3821, Australia. \\ G Curtin University of Technology, Muresk Institute, Northam, WA 6401, Australia. \\ ${ }^{\mathrm{H}}$ Corresponding author. Email: mike.mclaughlin@csiro.au
}

\begin{abstract}
Environmental Context. Cadmium is a potentially toxic metal that is an unwanted contaminant in urban wastewater biosolids, and has the potential to accumulate through the food chain. This study found that the accumulation of cadmium in wheat grain from application of urban biosolids to soils in Australia was less than when cadmium was applied in a water-soluble form. The critical soil cadmium concentration, above which wheat grain would exceed food contaminant limits, could also be simply predicted using soil pH (acidity) and clay content.
\end{abstract}

\begin{abstract}
One of the pathways for transfer of cadmium $(\mathrm{Cd})$ through the food chain is addition of urban wastewater solids (biosolids) to soil, and many countries have restrictions on biosolid use to minimize crop Cd contamination. The basis of these restrictions often lies in laboratory or glasshouse experimentation of soil-plant transfer of Cd, but these studies are confounded by artefacts from growing crops in controlled laboratory conditions. This study examined soil to plant (wheat grain) transfer of Cd under a wide range of field environments under typical agronomic conditions, and compared the solubility and bioavailability of $\mathrm{Cd}$ in biosolids to soluble Cd salts. Solubility of biosolid $\mathrm{Cd}$ (measured by examining $\mathrm{Cd}$ partitioning between soil and soil solution) was found to be equal to or greater than that of soluble $\mathrm{Cd}$ salts, possibly due to competing ions added with the biosolids. Conversely, bioavailability of Cd to wheat and transfer to grain was less than that of soluble $\mathrm{Cd}$ salts, possibly due to addition of $\mathrm{Zn}$ with the biosolids, causing reduced plant uptake or grain loading, or due to complexation of soluble $\mathrm{Cd}^{2+}$ by dissolved organic matter.
\end{abstract}

Keywords. agricultural chemistry — bioavailability — contaminant uptake — food quality — soil chemistry

Manuscript received: 16 October 2006.

Final version: 16 November 2006.

\section{Introduction}

Cadmium $(\mathrm{Cd})$ contamination of agricultural land is important due to public awareness and concern for food and land quality. Because of this, $\mathrm{Cd}$ residues in foods are regularly monitored by both national and international agriculture and health agencies in many parts of the world. Biosolids, a by-product from the treatment of urban wastewaters, contain valuable nutrients and organic matter, but also contain contaminants that can potentially affect soil, water, and food quality. Cadmium is the contaminant in biosolids most likely to adversely affect food quality because it is readily accumulated in the edible portion of crop plants at concentrations that may exceed food safety limits. ${ }^{[1]}$ Predicting the bioavailability of biosolid and soil $\mathrm{Cd}$ to agricultural crops has been an important goal of environmental chemists over many years. ${ }^{[2]}$

Assessing the bioavailability of metals in soils is bedevilled by experimental artefacts introduced through the study of soil-plant transfer of metals under laboratory and glasshouse conditions. For example, the addition of metals to soils may acidify soil and increase bioavailability, ${ }^{[3]}$ adding metal salts to soil increases the ionic strength of the soil solution, reduces metal sorption, and increases metal bioavailability, ${ }^{[4]}$ and study of soil-plant transfer of metals under glasshouse (or even lysimeter) conditions produces artificially high assessments of bioavailability compared to 
field conditions. ${ }^{[5]}$ In addition, $\mathrm{Cd}$ is rarely added to soils as a single contaminant, but usually with co-contaminants, nutrients, clay minerals or organic matter which may markedly affect $\mathrm{Cd}$ chemistry and plant $\mathrm{Cd}$ uptake. Hence, there has been criticism of the current body of literature on soil-plant transfer of $\mathrm{Cd}$, based solely on laboratory and glasshouse studies. ${ }^{[6-8]}$

At the same time, there are numerous examples where metal bioavailability to plants is higher when metals are applied to soil as soluble salts compared to metals added with biosolids. ${ }^{[9-12]}$ For example, significantly less Cd was taken up by lettuce grown on a long-term biosolid-amended soil than lettuce grown on soil amended with equivalent rates of Cd salt. ${ }^{[13]}$ However, this is not always the case. Knight et al. ${ }^{[14]}$ found that addition of $\mathrm{CdSO}_{4}$ to soil resulted in a smaller total soil solution $\mathrm{Cd}$ concentration than when biosolids were added to soil. Ahnstrom and Parker ${ }^{[15]}$ suggested that soil properties can have a significant influence on metal availability, regardless of the metal source.

This paper reports initial results from a large, multi-site, field-based study of soil physicochemical controls of $\mathrm{Cd}$ bioavailability. The data was used to develop a model to predict the plant accumulation of $\mathrm{Cd}$ from urban biosolids across a range of diverse soil types and to examine the bioavailability of biosolid Cd to plants.

\section{Materials and Methods}

Twelve field sites were established across Australia as part of a national series of multi-year trials examining the benefits and risks of biosolid reuse on agricultural land (the National Biosolids Research Program, NBRP). Plots were established which received increasing rates of both urban biosolids (in triplicate) and $\mathrm{Cd}$ chloride or sulfate salts (replicated

Table 1. Soil chemical properties and background $\mathrm{Cd}$ levels across the 12 sites used in the current study

\begin{tabular}{|c|c|c|}
\hline Property & Range & Mean \\
\hline $\mathrm{pH}_{\mathrm{C}}$ & $4.04-7.9$ & 5.6 \\
\hline $\mathrm{EC}\left[\mathrm{dS} \mathrm{m}^{-1}\right]$ & $0.06-0.38$ & 0.12 \\
\hline Total C [\%] & $0.9-5.7$ & 2.2 \\
\hline $\mathrm{CEC}\left[\mathrm{cmol}(+) \mathrm{kg}^{-1}\right]$ & $3.2-61.0$ & 14.9 \\
\hline Clay $[\%]$ & $3.9-65.5$ & 20.9 \\
\hline Total $\mathrm{Cd}\left[\mathrm{mg} \mathrm{kg}^{-1}\right]$ & $0.01-0.69$ & 0.10 \\
\hline
\end{tabular}

4 times). Biosolid rates applied were based on the nitrogen limited biosolid application rate (NLBAR) which is the amount of biosolids that can be added to a soil so there is no net accumulation of nitrogen after 1 year (i.e. the amount of mineralizable nitrogen added to the soil by the biosolid addition is equal to the amount taken up by the crop in one year). All biosolid field trials consisted of eight treatments - a control (unamended soil), a fertilizer control (according to normal farmers' practice), $0.25,1,1.5,3$ and 4.5 NLBAR as a single application and a 1.5 NLBAR per year repeat application. Cadmium salts and biosolids were added once to the plots at the start of the experimental program, and in addition one biosolid treatment received annual additions. Rates of $\mathrm{Cd}$ added to soil were designed using laboratory $\mathrm{Cd}$ sorption data (data not shown) to produce a range of soil solution $\mathrm{Cd}$ concentrations up to $250 \mathrm{nM}$. Note that these rates were well below those which could lead to toxicity to plants or soil organisms, ${ }^{[16]}$ and were designed to provide sufficient $\mathrm{Cd}$ to lead to crop $\mathrm{Cd}$ accumulation up to, and exceeding, current limit values (see below). The sites spanned a diverse range of climates and soils, from tropical (Ferrosols) to Mediterranean (Tenosols, Calcarosols) soil types ${ }^{[17]}$ and had a wide range of physicochemical characteristics (Table 1). Some chemical characteristics of the biosolids are presented in Table 2 .

Surface soil $(0-10 \mathrm{~cm})$ composite samples, consisting of up to twenty $1.5-\mathrm{cm}$ (minimum) diameter cores per plot, were taken from under the crop immediately after each crop harvest each year. All soil samples were dried under forced draft $\left(40^{\circ} \mathrm{C}\right)$, finely ground to pass a $<2.0-\mathrm{mm}$ sieve, and stored before analysis. All ground soil samples were analyzed to determine total $\mathrm{Cd}$ by graphite furnace atomic absorption spectrophotometry (GFAAS) following digestion with reverse aqua regia and (if necessary) filtration through a $0.45-\mu \mathrm{m}$ Millipore filter. Soil $\mathrm{pH}$ was measured in a $1: 5$ soil : $0.01 \mathrm{M} \mathrm{CaCl}_{2}$ extract while electrical conductivity was measured on a $1: 5$ soil: water extract. Total soil carbon was measured following combustion (Elemental analyser CNS2000, Leco, Baulkham Hills, NSW), while cation exchange capacity (CEC) was measured following extraction with ammonium chloride $\left(\mathrm{NH}_{4} \mathrm{Cl}\right)$ at either pH 7.0 or 8.5 , according to Rayment and Higginson. ${ }^{[18]}$ Particle size distribution [\% clay] was determined using the pipette method. ${ }^{[19]}$

Each year, soil pore waters were extracted by wetting air-dry soils up to a moisture potential of $-5 \mathrm{kPa}(\mathrm{pF} 1.7)$ using deionized water and incubating for $16 \mathrm{~h}$ before centrifugation. To extract soil solutions, soils were centrifuged at $2750 \mathrm{~g}$ for $30 \mathrm{~min}$ using the method of Thibault and Sheppard. ${ }^{[20]}$ Extracted solutions were then centrifuged at $25000 \mathrm{~g}$ for $60 \mathrm{~min}$ and filtered through a $0.45-\mu \mathrm{m}$ filter. The $\mathrm{pH}$ and $\mathrm{EC}$ of the solutions were determined immediately and Cd concentrations were determined by inductively coupled plasma mass spectroscopy (ICP-MS)

Various crops, including wheat, barley, triticale, canola, grasses, clover, peanuts, sorghum, maize, millet, sugarcane and cotton, were grown on the plots depending on local agronomic and climatic conditions. Crops were grown using best agronomic practices, harvested, and then the edible portions of crops were separated, dried, and after acid

Table 2. Chemical properties of biosolids used in the current study

\begin{tabular}{lccccrc}
\hline Biosolid & $\mathrm{pH}$ & $\begin{array}{c}\text { Total C } \\
{[\%]}\end{array}$ & $\begin{array}{c}\text { Total N } \\
{[\%]}\end{array}$ & $\begin{array}{c}\text { Total Cd } \\
{\left[\mathrm{mg} \mathrm{kg}^{-1}\right]}\end{array}$ & $\begin{array}{c}\text { Total Cu } \\
{\left[\mathrm{mg} \mathrm{kg}^{-1}\right]}\end{array}$ & $\begin{array}{c}\text { Total Zn } \\
{\left[\mathrm{mg} \mathrm{kg}^{-1}\right]}\end{array}$ \\
\hline Bolivar AAD & 7.4 & 6.3 & 0.77 & 1.8 & 315 & 435 \\
Bolivar BDB & 7.4 & 8.6 & 0.98 & 2.2 & 340 & 500 \\
Vic Goulburn V. Water & 7.1 & 6.5 & 0.83 & 1.4 & 65 & 180 \\
Vic North East Water & 5.0 & 11.6 & 2.03 & 0.9 & 100 & 300 \\
Vic Gippsland Water & 5.6 & 20.4 & 2.85 & $<0.5$ & 70 & 180 \\
Vic E. Gippsland Water & 4.6 & 10.6 & 1.25 & 1.0 & 150 & 290 \\
NSW Malabar & 7.6 & 20.3 & 1.55 & 5.4 & 420 & 650 \\
NSW Bondi & 5.9 & 28.7 & 2.50 & 4.6 & 880 & 870 \\
Qld Noosa & 6.8 & 27.2 & 4.79 & 1.9 & 355 & 495 \\
Qld Luggage Point & 6.6 & 32.8 & 5.72 & 3.5 & 830 & 1705 \\
WA Woodman Point & 6.9 & 32.2 & 5.17 & 2.0 & 1500 & 900 \\
WA Beenyup & 6.8 & 34.7 & 5.54 & 1.4 & 1170 & 615 \\
\hline
\end{tabular}


digestion (in concentrated $\mathrm{HNO}_{3}$ ), Cd concentrations in plant shoots and/or edible portions were determined by GFAAS or ICP-MS. Crop species vary widely in their accumulation of $\mathrm{Cd}$ in edible parts, so to develop a model which explained the effects of soil physicochemical conditions on Cd uptake, a single species was chosen (wheat).

Reactivity or availability of salt and biosolid Cd was expressed as a partition coefficient $\left(K_{\mathrm{d}}\right)$, which describes $\mathrm{Cd}$ distribution between soil and soil pore water as follows:

$$
K_{\mathrm{d}}\left[\mathrm{L} \mathrm{kg}^{-1}\right]=\frac{\text { Total soil Cd concentration }\left[\mathrm{mg} \mathrm{kg}^{-1}\right]}{\text { Soil pore water concentration }\left[\mathrm{mg} \mathrm{L}^{-1}\right]}
$$

The relative plant availability and food chain risk of biosolid and metal-salt $\mathrm{Cd}$ was compared by calculating a bioconcentration factor $(\mathrm{BCF})$ for wheat grain for each individual plot as follows:

$$
\mathrm{BCF}=\frac{\text { Crop Cd concentration }\left[\mathrm{mg} \mathrm{kg}^{-1}\right]}{\text { Soil Cd concentration }\left[\mathrm{mg} \mathrm{kg}^{-1}\right]}
$$

Each BCF was calculated from an average grain Cd concentration for that plot divided by the total soil $\mathrm{Cd}$ concentration determined in the bulked surface soil sample described above. Differences between $\mathrm{Cd}$ sources for relationships between $K_{\mathrm{d}}$ and solution Cd, and between BCF values and soil $\mathrm{Cd}$, were determined using grouped and separate linear regression analysis using GenStat 8 (VSN International, Hertz, UK).

Critical soil (total) $\mathrm{Cd}$ concentrations at which wheat grain exceeded the Food Standards Australia New Zealand (FSANZ) Maximum Level $\left(0.1 \mathrm{mg} \mathrm{kg}^{-1}\right.$ fresh weight) were calculated from the relationship between soil and grain $\mathrm{Cd}$ at each site, and these critical soil $\mathrm{Cd}$ concentrations were regressed (multiple step-wise forward) against relevant soil physicochemical properties to develop a model to predict food chain risk from soil $\mathrm{Cd}$.

\section{Results and Discussion}

There was a negative relationship $(P<0.001)$ between the magnitude of the $\mathrm{Cd}$ partitioning coefficient and $\mathrm{Cd}$ loading (i.e. soil solution Cd concentration) (Fig. 1), indicating a curvilinear relationship between solution and solid phase $\mathrm{Cd}$ caused by weaker $\mathrm{Cd}$ binding at higher $\mathrm{Cd}$ loadings. ${ }^{[21]}$ There was a small but significant $(P<0.001)$ difference in $\mathrm{Cd}$ partitioning between the biosolids and the $\mathrm{Cd}$ salt treatments, indicating that for each unit $\mathrm{Cd}$ added by these sources, soil pore water $\mathrm{Cd}$ concentrations would be greater for biosolid $\mathrm{Cd}$. Indeed, the slope of the relationship between $K_{\mathrm{d}}$ and soil solution $\mathrm{Cd}$ for biosolids was $25 \%$ more negative than for $\mathrm{Cd}$ salt, i.e. more $\mathrm{Cd}$ was soluble in soils treated with biosolids

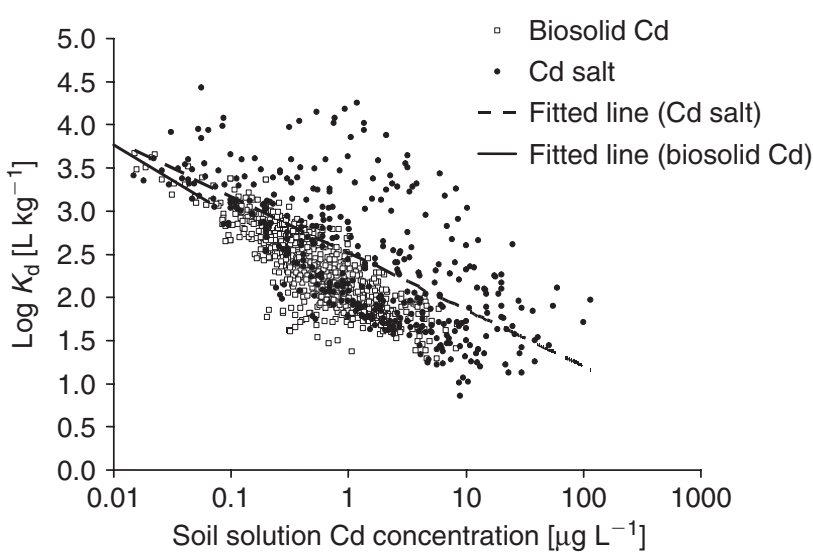

Fig. 1. Partitioning coefficient $\left(K_{\mathrm{d}}\right)$ for soluble and biosolid Cd across all sites. Each point represents the partitioning of $\mathrm{Cd}$ in that plot based on the analysis of a subsample of up to 20 bulked $0-10-\mathrm{cm}$ soil samples. (at equivalent solution $\mathrm{Cd}$ loadings). Differential soil $\mathrm{pH}$ between the biosolid and $\mathrm{Cd}$ salt treatments was not implicated in this difference in Cd partitioning (Fig. 2). These data do not support the hypothesis that minerals and/or organic matter added to soils through biosolids addition play a strong role in minimizing $\mathrm{Cd}$ solubility in soils through enhanced sorption. ${ }^{[2]}$ Indeed, the greater solubility of biosolid $\mathrm{Cd}$ compared to salt $\mathrm{Cd}$, may have been due to several changes in soil physicochemistry induced by the biosolids such as higher concentrations of dissolved organic matter, competing cations (e.g. $\mathrm{Ca}, \mathrm{Zn}$, etc.) or reduced $\mathrm{pH}$ in soil solutions in biosolid-treated soils. These are still under investigation.

Grain accumulation of Cd was highly dependent on soil type with significantly different critical soil Cd concentrations at each site; an example of the relationships obtained at two sites is shown in Fig. 3. Soil pH and soil clay content were good predictors of the critical soil Cd concentration (Fig. 4), given the wide range of soil and environmental conditions encountered.

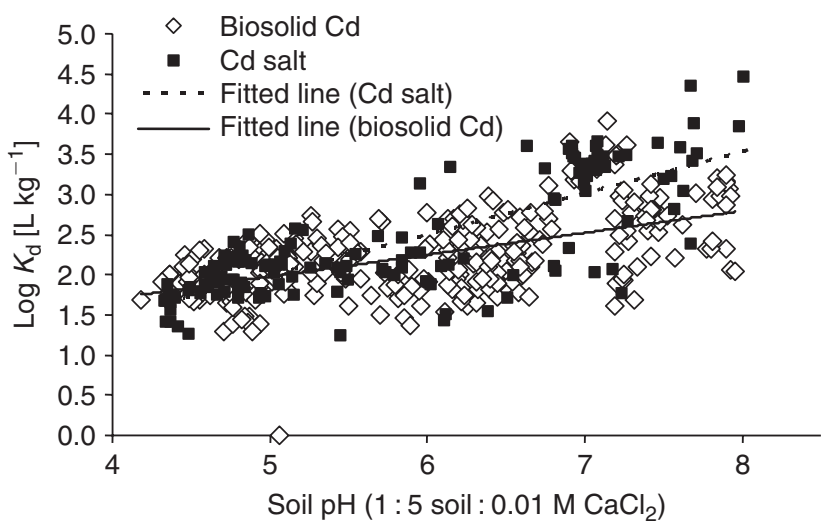

Fig. 2. Partitioning coefficient $\left(K_{\mathrm{d}}\right)$ for soluble and biosolid Cd across all sites in relation to soil $\mathrm{pH}$. Each point represents the partitioning of $\mathrm{Cd}$ in that plot based on the analysis of a subsample of up to 20 bulked $0-10-\mathrm{cm}$ soil samples. The fitted lines were significantly different $(P<0.001)$.

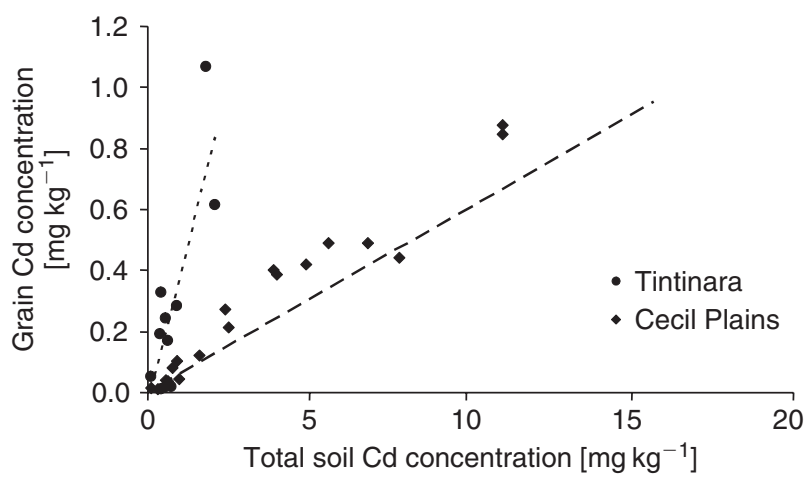

Fig. 3. Wheat grain $\mathrm{Cd}$ concentration $\left[\mathrm{mg} \mathrm{kg}^{-1}\right]$ as affected by addition of $\mathrm{Cd}$ salts to two sites. The Tintinara soil had a $\mathrm{pH}$ of 6.3 and a clay content of $10 \%$, Cecil Plains had a soil $\mathrm{pH}$ of 7.9 and a clay content of $66 \%$. Fitted lines are: Tintinara grain $\left.\mathrm{Cd}^{\mathrm{mg} \mathrm{kg}}{ }^{-1}\right]=0.42$ (total soil $\left.\mathrm{Cd} \mathrm{mg} \mathrm{kg}{ }^{-1}\right]-0.04, R^{2}=0.68$; Cecil Plains grain $\mathrm{Cd}\left[\mathrm{mg} \mathrm{kg}^{-1}\right]=0.08$ (total soil $\mathrm{Cd} \mathrm{mg} \mathrm{kg}^{-1}$ ) $+0.02, R^{2}=0.96$. 


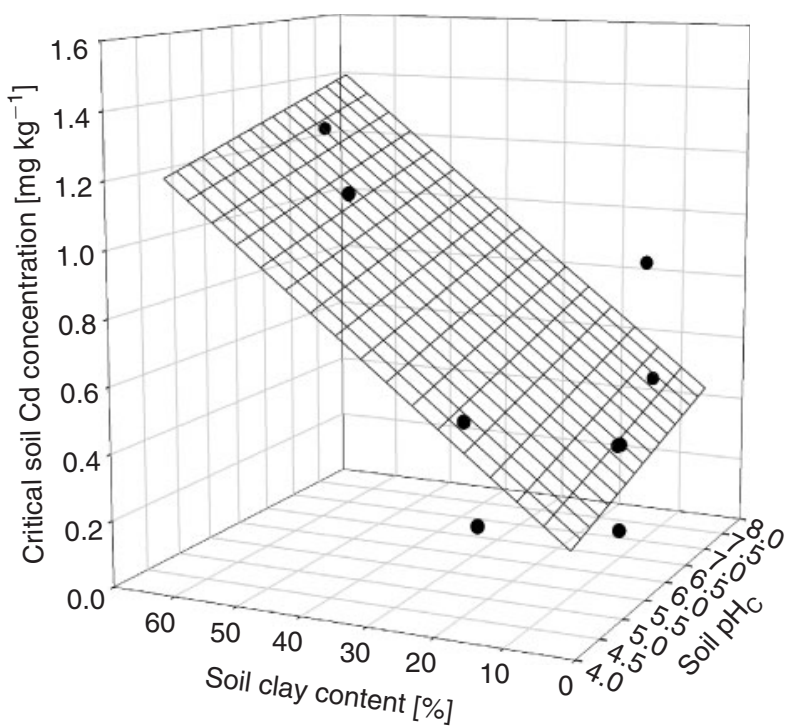

Fig. 4. Three-dimensional model to explain the effect of soil physicochemical characteristics on accumulation of $\mathrm{Cd}$ by wheat grain (data from $\mathrm{Cd}$ salt treatments). Critical soil $\mathrm{Cd}$ concentrations at each site were determined from regressions of grain $\mathrm{Cd}$ concentrations against total soil $\mathrm{Cd}$ concentrations. Critical soil $\mathrm{Cd}$ concentrations were then modelled using soil physicochemical characteristics. The fitted surface was: critical soil Cd concentration $\left[\mathrm{mg} \mathrm{kg}^{-1}\right]=0.067 \times \mathrm{pH}+0.015 \times$ clay content $[\%]-0.12: R^{2}=0.75$.

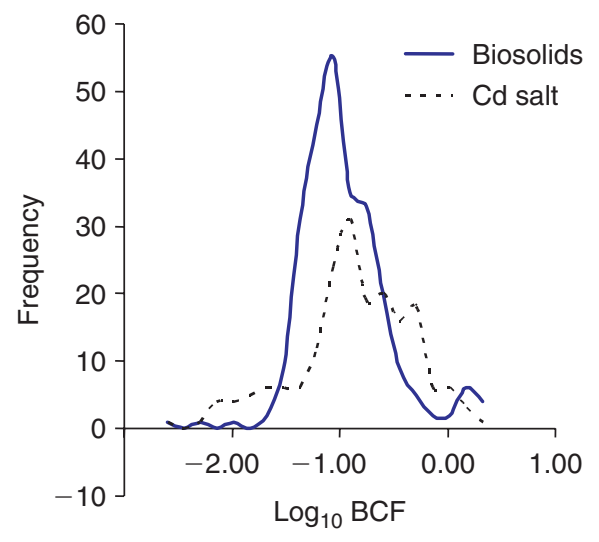

Fig. 5. Frequency histogram for the bioconcentration factor $(\mathrm{BCF})$ for wheat grown on soils treated with soluble or biosolid Cd. Each BCF was calculated from an average grain $\mathrm{Cd}$ concentration for that plot divided by the total soil $\mathrm{Cd}$ concentration determined in up to 20 bulked $0-10$-cm soil samples taken across each plot.

To compare the accumulation of $\mathrm{Cd}$ from biosolids to that from metal salts, the frequency distribution of BCF values of biosolid Cd was compared to the frequency distribution of BCFs for metal salt Cd across all plots (Fig. 5). Wheat grain $\mathrm{BCF}$ values spanned a wide range, from less than 0.003 to values greater than 1 , at which point there were equal $\mathrm{Cd}$ concentrations in the grain and in the soil. Frequency distributions of $\mathrm{BCF}$ values for salt and biosolid $\mathrm{Cd}$ were not significantly different.

The $\mathrm{BCF}$ for $\mathrm{Cd}$ decreased with increasing soil $\mathrm{Cd}$ concentration $(P<0.001)$. There was a significant $(P<0.001)$

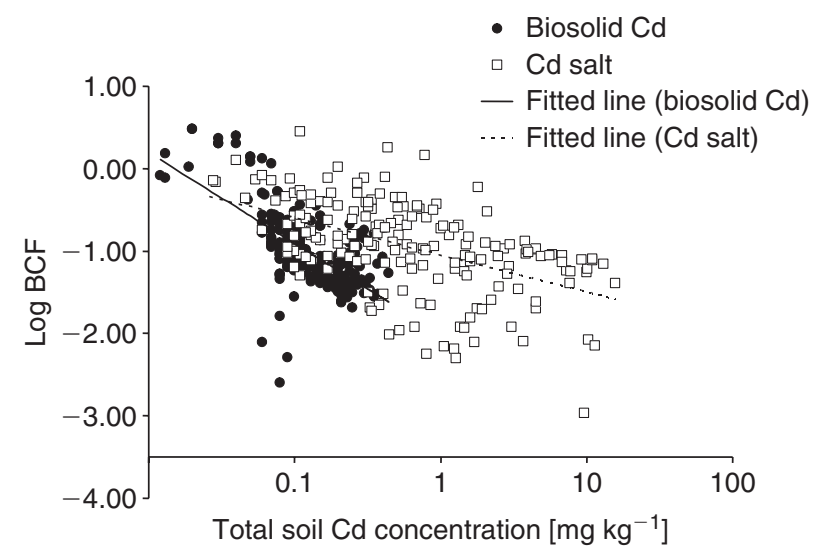

Fig. 6. Bioconcentration factors $(\mathrm{BCF})$ for soluble and biosolid $\mathrm{Cd}$ across all sites. Each point represents the bioaccumulation of $\mathrm{Cd}$ by wheat grain in that plot based on the analysis of a subsample of the wheat grain, and from an analysis of up to 20 bulked $0-10-\mathrm{cm}$ soil samples.

difference between the bioavailability of biosolid $\mathrm{Cd}$ and salt $\mathrm{Cd}$ to wheat plants. In contrast to the $\mathrm{Cd}$ partitioning data, at equal soil $\mathrm{Cd}$ loading biosolid $\mathrm{Cd}$ was less available to plants than salt $\mathrm{Cd}$. Overall, the difference in slopes of the relationship between BCF and soil Cd was 2.5 -fold $(P<0.001)$, meaning that biosolid $\mathrm{Cd}$ was much less available than salt $\mathrm{Cd}$ at equivalent soil $\mathrm{Cd}$ loadings. At low total concentrations of soil $\mathrm{Cd}\left(\sim 0.1 \mathrm{mg} \mathrm{kg}^{-1}\right)$, the absolute difference in bioaccumulation was approximately 2 -fold, and at higher soil Cd concentrations $\left(\sim 0.5 \mathrm{mg} \mathrm{kg}^{-1}\right)$ it increased to over 5 fold. Two mechanisms (still under investigation) may be responsible for this:

(1) addition of co-contaminants in biosolids which competitively inhibit uptake of biosolid $\mathrm{Cd}$ by plants e.g. Zn; and/or

(2) dissolved organic matter reducing the availability of $\mathrm{Cd}$ in soil solution to plants through complexation of free $\mathrm{Cd}^{2+}$.

However, at low soil Cd loadings more typical of normal biosolid use (total $\mathrm{Cd}<0.5 \mathrm{mg} \mathrm{kg}^{-1}$ ), the difference in availability between the $\mathrm{Cd}$ sources is less pronounced (Fig. 6). This difference in availability, while small, still needs to be considered in the development of regulatory controls of $\mathrm{Cd}$ added to soils in biosolids.

Some soil types also allow greater soil-plant transfer of $\mathrm{Cd}$ than others. The BCF data shown in Fig. 6 indicate that high risk soils could have BCF values as high as 2 ( $\log \mathrm{BCF}$ of 0.3$)$, meaning that if soil $\mathrm{Cd}$ concentrations are $0.1-0.2 \mathrm{mg} \mathrm{kg}^{-1}$ (levels only slightly elevated from typical background values), crop Cd concentrations could reach $0.2-0.4 \mathrm{mg} \mathrm{kg}^{-1}$ (the FSANZ ML for wheat, peanuts and vegetables is $\left.0.1 \mathrm{mg} \mathrm{kg}^{-1}\right)$. It is important that biosolids are not used on these high risk soils, and the NBRP trials are producing data that will help to identify which soils are of greatest risk. At this stage, high risk soils seem to be those with low $\mathrm{pH}$ and low clay content. 


\section{Conclusions}

Cadmium in biosolids has a similar solubility to that in soluble $\mathrm{Cd}$ salts, but the availability and translocation of $\mathrm{Cd}$ to wheat grain from biosolids is significantly lower than $\mathrm{Cd}$ from salts. It is likely that co-contaminants in the biosolid (e.g. Zn or dissolved organic carbon) contribute to the lower bioavailability and food chain transfer of biosolid Cd. A simple model combining soil $\mathrm{pH}$ and clay content was very successful in describing the risk of $\mathrm{Cd}$ accumulation in wheat grain. This will allow improvement to guidelines regarding safe levels of $\mathrm{Cd}$ in soils receiving biosolids.

\section{Acknowledgements}

The NBRP gratefully acknowledges its numerous financial supporters (see http://www.awa.asn.au/Content/Navigation Menu2/ResourceCenter/BiosolidsManagement/NationalBio solidsResearchProgram/default.html). The authors would like to acknowledge Daryl Stevens, Kris Broos, Nancy Penney, Cathy Fiebiger, Cameron Baldock, Gillian Cozens, Ashlyn Daly, Anita Pastuhova, George Pollard, Michelle Smart, David Collins, Jo Stokes, Mathew Boomsma, Bogumila Tomczak and Tapas Biswas for assistance, and Ray Correll and Mary Barnes for advice on experimental design and statistical analysis.

\section{References}

[1] R. L. Chaney, D. P. Oliver, in Contaminants in the Soil Environment in the Australasia-Pacific Region (Eds R. Naidu, R. Kookana, D. P. Oliver, S. R. Rogers, M. J. McLaughlin) 1996, pp. 456-478 (Kluwer Publishers: Dordrecht, The Netherlands).

[2] M. J. McLaughlin, B. A. Zarcinas, D. P. Stevens, N. Cook, Commun. Soil Sci. Plant Anal. 2000, 31, 1661.

[3] T. W. Speir, H. A. Kettles, H. J. Percival, A. Parshotam, Soil Biol. Biochem. 1999, 31, 1953. doi:10.1016/S0038-0717(99)00115-7

[4] D. P. Stevens, M. J. McLaughlin, T. Heinrich, Environ. Toxicol. Chem. 2003, 22, 3017. doi:10.1897/02-290
[5] M. P. C. De Vries, K. G. Tiller, Environ. Pollut. 1978, 16, 231. doi:10.1016/0013-9327(78)90118-0

[6] R. L. Chaney, in Metal Speciation - Theory, Analysis and Application (Eds J. R. Kramer, H. E. Allen) 1988, pp. 219-260 (Lewis Publishers: Chelsea, MI).

[7] I. M. McKenna, R. L. Chaney, F. M. Williams, Environ. Pollut. 1993, 79, 113. doi:10.1016/0269-7491(93)90060-2

[8] N. T. Basta, J. A. Ryan, R. L. Chaney, J. Environ. Qual. 2005, $34,49$.

[9] J. D. Cunningham, D. R. Keeney, J. A. Ryan, J. Environ. Qual. 1975, 4, 460.

[10] J. D. Cunningham, D. R. Keeney, J. A. Ryan, J. Environ. Qual. 1975, 4, 448.

[11] J. D. Cunningham, J. A. Ryan, D. R. Keeney, J. Environ. Qual. 1975, 4, 455.

[12] A. C. Chang, T. C. Granato, A. L. Page, J. Environ. Qual. 1992, $21,521$.

[13] S. L. Brown, R. L. Chaney, J. S. Angle, J. A. Ryan, J. Environ. Qual. 1998, 27, 1071.

[14] B. P. Knight, A. M. Chaudri, S. P. McGrath, K. E. Giller, Environ. Pollut. 1998, 99, 293. doi:10.1016/S0269-7491(98)00021-9

[15] Z. A. S. Ahnstrom, D. R. Parker, Environ. Sci. Technol. 2001, 35, 121. doi:10.1021/ES001350O

[16] S. P. McGrath, in Cadmium in Soils in Plants (Eds M. J. McLaughlin, B. R. Singh) 1999, pp. 199-218 (Kluwers Academic Publishers: Dordrecht, The Netherlands).

[17] R. K. Isbell, The Australian Soil Classification 1996 (CSIRO Publishing: Melbourne).

[18] G. R. Rayment, F. R. Higginson, Australian Laboratory Handbook of Soil and Water Chemical Methods 1992 (Inkata Press: Melbourne).

[19] G. W. Gee, J. W. Bauder, in Methods of Soil Analysis: Part 1: Physical and Mineralogical Methods (Ed. A. Klute) 1986, pp. 383-411 (American Society for Agronomy/Soil Science Society of America: Madison, WI).

[20] D. H. Thibault, M. I. Sheppard, Commun. Soil Sci. Plant Anal. 1992, 23, 1629.

[21] L. L. Hendrickson, R. B. Corey, Soil Sci. 1981, 131, 163. doi:10.1097/00010694-198103000-00006

[22] G. M. Hettiarachchi, J. A. Ryan, R. L. Chaney, C. M. La Fleur, J. Environ. Qual. 2003, 32, 1684. 